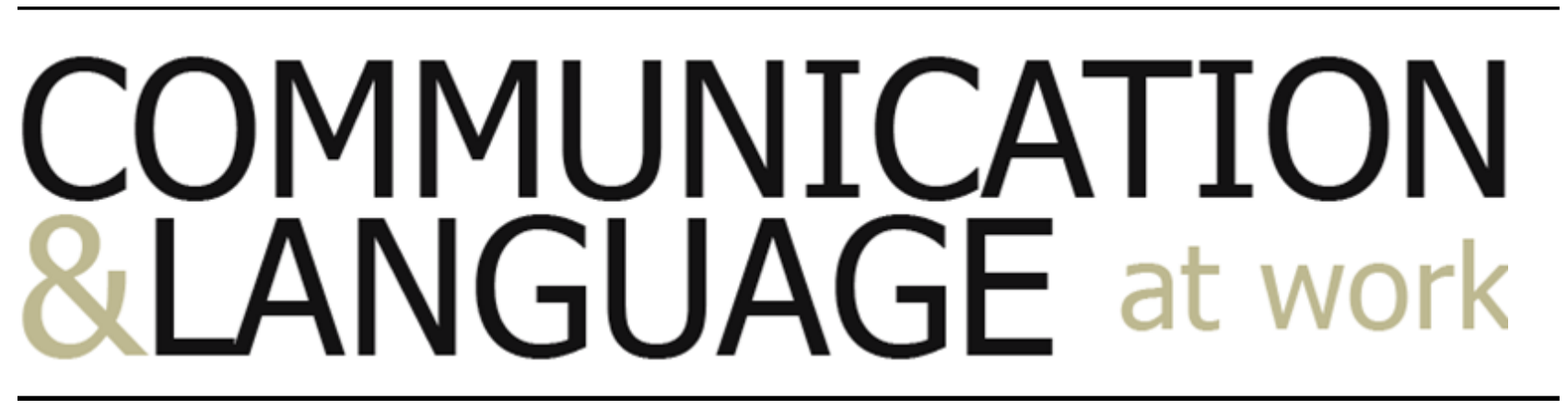

\title{
Communication as constitutive of work practices.
}

\section{An outlook on work-related interaction as portrayed by Communication \& Language at Work.} Editorial

\author{
Klarissa Lueg \\ Associate Professor of Corporate Communication, University of Southern Denmark \\ klueg@sdu.dk \\ Peter Kastberg \\ Professor of Communication and culture in professional context, Aalborg University, Department of Culture and \\ Global Studies \\ kastberg@cgs.aau.dk
}

\section{Introduction}

This issue marks a new stage in the history and development of Communication \& Language at Work (CLaW). Personal, organizational, and programmatic changes have been induced in order to revive and continue CLaW. Up until now, ClaW has been published by Peter Kastberg, Aalborg University (AAU) - hitherto under the title "Language at Work" - since 2006. Peter Kastberg, long-time head, and founder, of the journal, will remain Editor, but is now sharing responsibility with Klarissa Lueg, Associate Professor at University of Southern Denmark (SDU). As of now, many of the main editorial and administrative functions will take place at the University of Southern Denmark, Campus Kolding, whilst other editorial processes will be overseen by both Editors, based at AAU and SDU, respectively. This cooperation marks a new beginning for CLaW, in which the journal will be suspended in a larger network of scholars, spanning not only three large Danish universities, but also associates from other, international institutions. The editorial team has also been looking at ways to adapt the journal's aims and scopes to more contemporary demands and developments. CLaW's programmatic description, consequently, has changed substantially and now embraces a broad, mostly philosophical and sociological fed, stance on communicative practices at work.

This editorial is meant to, first, explain some of these changes and, second, to elaborate on our aims, and distinctiveness, as a journal in the context of a broad and heavily competitive journal and publishing house market.

Firstly, as to the personal changes, the main work of the journal has been conducted by Peter Kastberg, who, in 2017, was close to discontinuing the journal due to increasing demands on academic work. The journal, that can look back on a 12-years-long history of publishing articles, would have left a void in the journal landscape dedicated to communication and work processes, especially with a view to being an outlet for Danish and other Scandinavian researchers. Several factors prevented the journal from being discontinued: Klarissa Lueg, Associate Professor at SDU, and a former coworker and author of the journal, joined as Editor, SDU generously offered the first financial support needed, and the appointment of Peter Kastberg as Full Professor at Aalborg University set free additional resources to secure administrative processing of CLaW for the foreseeable future. In lieu of this, CLaW has emancipated itself from previous ties to professional organizations. Instead, CLaW now operates as a fully independent, open access journal 
governed by the two editors and a growing, international editorial board. The journal, further, is embedded in several research networks and centers, that connect, thematically, to CLaW's aims and scopes. First, there is the Communicating Organizations Research Group, located, located at the Department of Culture and Global Studies, AAU, secondly, there is the SDU-based Center for Narratological Studies, with its international network for narrative research, connecting researchers from Denmark internationally. These networks are important intellectual bases for CLaW.

The board has been renewed, completely, except for the founding editor. Associate editors agree to collaborate for a three-year term, renewable by agreement. All associate editors will be invited to an annual board meeting.

Finally, we want to assert what this Journal is about, and, equally important, what it is not about. Communication \& Language at Work, obviously, contains three keywords: communication, language and work. To us, these three keywords, in this exact combination, make sense and provide the basis for numerous (critical) perspectives on what constitutes (communication) tangible interaction (language) in daily human encounters (work).

Starting with communication, we are interested in communication as displayed by theories of action, that is, social, and discursive practices of communication as conducted by agents, embedded in and relating to social structures (e.g. Giddens, 1984). That is, we take no interest in positivistic approaches to, e.g., the functional vein of corporate communication with the mere purpose of corporate application or practice reaffirmation. Instead, we view subfields of communication - from strategic organizational communication to intercultural communication - as constructed by interacting agents and the social settings they are associated with (e.g. Schöneborn \& Blaschke, 2014). Critical approaches as to, e.g., power or knowledge asymmetries (e.g. Mumby, 2013, and Alvesson, 1996), and how these impacts on communicative practices are especially welcomed.

Language, the second keyword, is considered as a means of communication, however a vital one. In language, the above mentioned power and knowledge asymmetries, historical inequalities and contemporary valuations condense (e.g. Bourdieu, 1991). Language, thus, heavily impact, on how agents can act within work settings and how they and the positions and official functions assigned to them are viewed and assessed. Corporate and organizational language, further, holds power to motivate or alienate people, and to pave way for institutionalizing meanings and valuations.

As to the last keyword, work: in times of increasing interest in the notion of "organization" choosing "work" might seem almost anachronistic. Obviously, coming from sociology, philosophy, and critical sociolinguistics, we have an interest in organizational settings. CLaW is one amongst many, thereunder brilliant, journals, that want to shed light on processes of human interaction in companies, NGOs, governance bodies and the like. Submissions as to these topics are more than welcomed by the editors. However, we also want to include investigations into work as a non-organizational issue, that is, research pertaining to settings, where work is not graspable with the usual notions of organizational research. Constraining work to organizational affiliations means incorporating and reproducing a social privilege: not all work takes place within or affiliated with an organization. The notion of work, as we understand it, may also invite research into nonmarket work (such as being a family caregiver, a house wife, or a stay-at-home-mom) (Johnson, 2013; Minton \& Libman Block, 1983), precarious work (such as being a freelancer detached from clear organizational settings and benefits), and emotional investments and leisure activities (such as coordinating friendships and acquaintances), that can, not least referring to Bourdieu's notions of social capital and exchange (Bourdieu, 1997, 2005) be described as work. Finally, "illegal" and marginalized settings, human trafficking and unorganized sex work, call for investigation, as well. All of these work settings are, as we see it, suspended in a net of communicative processes (viz. discourses or narratives), that construct their social position, their value, and that are both influences by and, vice versa, impact on the practices of the agents involved.

By possibly combining these notions, we hope to capture interesting insights into a highly relevant social field. This does not mean that submissions centering on only one or two aspects of the abovementioned elaborations will not be considered - we acknowledge that each aspect is also a field of study in its own right. Equally, we hope to be challenged in our views and wish to promote novel and innovative stances that we had not considered previous to conceptualizing CLaW's purpose. Special issue proposals are welcome, and so are inter- and transdisciplinary approaches. This means, among other things, that CLaW will not accept contributions with an exclusively corporatist view on communication, that is, proposing communicative solutions to corporate or political leadership challenges without a critical view on hegemonial dependencies.

This combination of notions, and the (however not exclusive) focus on linguistic practices, makes CLaW distinct. This distinctness is completed by our outlook on what a publishing outlet should be: In our daily academic life, we witness 
great thoughts on an everyday basis, be it in research group discussions, conceptual workshops, speeches or drafts of research projects. Though not all of these forms can be given publishing opportunity, in CLaW we wish to provide a forum for researchers to document their thoughts in - nowadays - uncommon forms. We therefore also accept (coherent) notes, speeches and discussion protocols of high quality. Practicing what we preach, we consider academic discourse as constitutive of the valuation of the scholarly profession. Though research articles are the central outlet for academic thought and insights, communication taking place beyond that, increasingly standardized, form are worth being documented, as well.

In the next years, we hope to push that agenda further whilst further improving the journal's quality and expanding our networks. CLaW, as an open access journal, is not attached to a publishing house, and thus depends on the work of its supporters and network associates. We are grateful to all that have supported CLaW in its 12-year history and in its current restructuring process, including Per Krogh Hansen, head of department of Design and Communication, SDU, as well as the head of Culture and Global Studies, AAU, Marianne Rostgaard. We hope to make CLaW the natural publishing forum for research into communication, language and work and look forward to an exciting collaboration with our board members and authors.

\section{References}

Alvesson, M. (1996). Communication, Power and Organization. Berlin / New York: Walther de Gruyter.

Bourdieu, P. (1991). Language and Symbolic Power. Cambridge, MA: Harvard University Press.

Bourdieu, P. (1997). The Forms of Capital. In A. H. Halsey, H. Lauder, P. Brown, \& A. S. Wells (Eds.), Education, Culture, Economy, Society (pp. 46-58). Oxford: Oxford University Press.

Bourdieu, P. (2005). The Social Structures of the Economy. Cambridge: Polity.

Giddens, A. (1984). The Constitution of Society : Outline of the Theory of Structuration. Cambridge: Polity.

Johnson, K. R. (2013). Nonmarket work. In V. Smith (Ed.), Sociology of work: an encyclopedia (pp. 628-629). Thousand Oaks, California: SAGE Publications, Inc. Retrieved from http://sk.sagepub.com/reference/sociology-of-work. doi:10.4135/9781452276199

Minton, M. H., \& Libman Block, J. (1983). What Is a Wife Worth? The Leading Expert Places a High Dollar Value on Homemaking. New York: William Morrow.

Mumby, D. K. (2013). Organizational Communication: A Critical Approach. Los Angeles et al.: Sage. Schöneborn, D., \& Steffen Blaschke (2014). The Three schools of CCO thinking: interactive dialogue and systematic comparison. Management Communication Quarterly, vol 28(2), 285-316.

Schöneborn, D., \& Steffen Blaschke (2014). The Three schools of CCO thinking: interactive dialogue and systematic comparison. Management Communication Quarterly, vol 28(2), 285-316 